\title{
FEV HiFORS: A new passenger car Diesel injector with continuous rate shaping for 2500 bar injection pressure
}

\begin{abstract}
This paper presents the HiFORS continuously rate shaping injector for injection pressures of 2500 bar and above developed by FEV GmbH and the Institute for Combustion Engines, RWTH Aachen University. The development process from concept definition to hydraulic and deisgn layout, material choice and manufacturing is discussed. The hydraulic operating properties are verified by injection test rig investigations. Optical investigations are conducted in an optically accessible high pressure, high temperature chamber using shadowgraphy and OH chemoluminescence detection, thereby capturing both liquid and gaseous penetration as well as combustion areas. Single cylinder investigations are carried out at a $0.4 \mathrm{dm}^{3}$ research engine in different operating points from low part load to full load. Compared to a serial production piezo injector, base measurements using conventional square injection profiles already show reduced combustion noise at improved $\mathrm{NO}_{x}$-soot trade-off as well as lowered $\mathrm{HC}$ and CO emissions. Detailed investigations at part load operating points explore the potential of different continuous rate shaping patterns, while the injector's high injection pressure capability of up to 2500 bar and its influence on engine performance is tested at full load operation points.
\end{abstract}

Key words: Diesel Injection System, Injection Hydraulics, Mixture Formation

\section{Introduction}

Increasing energy cost as well as fiscal incentives for low $\mathrm{CO}_{2}$ emission vehicles are strong drivers towards efficient drivetrain concepts, resulting in a constantly high request for Diesel engine driven passenger cars especially in Europe. Despite of its outstanding thermodynamic efficiency, the intrinsic pollutant emissions of the Diesel engine, mainly nitrogen oxides and particulate matter, pose a significant challenge against the background of strict European emission regulation. Exhaust gas aftertreatment systems, although technically mature and highly efficient, considerably contribute to drivetrain cost both for manufacturers and, in the form of increased fuel or additional AdBlue consumption, also for customers. In addition, increasingly efficient combustion processes resulting in low exhaust gas temperatures are a limiting factor for aftertreatment effectiveness especially in test cycle relevant cold start conditions.

Due to these considerations, combustion process optimization not only towards low fuel consumption but also minimized pollutant emission is gaining in importance; at the same time, combustion noise has to remain as low as possible to satisfy tight $\mathrm{NVH}$ requirements. The fuel injection system is one of the main determining factors in achieving these targets: today, commercially available passenger car common rail systems employ pressures up to 2500 bar [1] and sophisticated multiple injection patterns to optimize mixture formation for combustion processes utilizing high boosting pressures and exhaust gas recirculation (EGR) rates.

Injection rate shaping and its potential to further improve combustion development have been approached in numerous investigations in research and development. Out of the need for low complexity and high cost-effectiveness of commercial systems, the main path in the automotive industry goes towards discontinuous processes using latest servo injector designs or directly controlled injectors which allow for a high number of single injection events at shortest dwell times, thereby blurring the line between multiple injection and digital rate shaping. However, when used for continuous rate shaping, directly controlled injectors have to face the drawbacks of needle seat throttling on mixture formation [2]. On the other side, most experimental systems for pressure modulated continuous rate shaping have a high system complexity with additional high pressure components and / or control elements which may be difficult to integrate into an engine concept outside of the laboratory.

FEV and VKA's approach of fully integrating a pressure modulation system into a standard-sized passenger car injector has overcome these challenges. The new high pressure fast opening rate shaping (HiFORS) injector has been specifically designed for state of the art injection pressures of up to 2500 bar combined with completely flexible continuous rate shaping and shortest needle opening and closing times, thus avoiding needle seat throttling as far as possible.

\section{HiFORS injector}

The HiFORS (High Pressure / Fast Opening / Rate Shaping) injector has been developed with the aim to provide a highly flexible tool for use in the development and study of state-of-the-art diesel combustion processes. Considerations particularly include the operation with both high EGR rates and high boost pressures and the consequent demand for high injection pressures [3] as well as the option of combustion shaping on the basis of advanced control concepts $[4,5,6]$. Against this background, the following development objectives have been set for the new injector:

- Injection pressures up to 2500 bar

- Injection rate shaping ability

- High needle opening and closing speeds.

Additional demands include lowest possible leakage, which allows efficient injection system operation at high injection pressures, as well as integration feasibility in 
a state-of-the-art diesel engine cylinder head. This means significant restrictions on the amount of space available for the individual injector components.

Similar to the former FEV FIRST injector [7], the HiFORS features a two-stage hydraulic servo system which transforms the actuation voltage of a single piezo actuator into a corresponding injection pressure. In this concept, the injector does not need any additional actuation elements or connections.

\subsection{Design concept}

The aim of the injector design, see Fig. 1, is to find a modular concept which provides maximum flexibility for the use of the individual components in addition to the functional flexibility of the injector. The individual injector functions are carried out by separate modules. These can be exchanged individually exists or in groups to adapt to changing operating conditions such as different fuels.

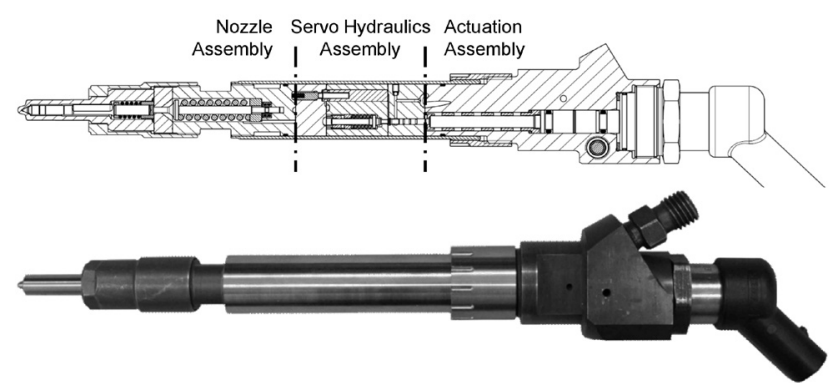

Fig. 1. HiFORS injector

The actuation assembly, the servo hydraulics assembly and the nozzle assembly form the main subsystems of the injector. A clamping sleeve connects the modules to each other and applies a sufficiently high contact pressure to the contact planes between the components to ensure the tightness of the high pressure loaded areas even at the highest supply pressures.

The actuation assembly is enclosed by the connector body which carries the hydraulic fittings for high pressure inlet and drain as well as the electrical connections of the integrated sensors and a piezo module taken from a serial production injector. Inside the connector body, the extension of the piezoelectric element is transmitted to the subsequent servo hydraulic assembly by a transmission module which can be carried out with or without a hydraulic coupler.

The injection rate shaping functionality is carried out by the servo hydraulics assembly. A pilot valve transmits the movement of the piezo module into a control pressure. The control pressure actuates the main valve, which in turn controls the injection pressure which is fed to the to the nozzle assembly. The current configuration is a compromise between the least possible permanent leakage and optimum hydraulic performance, using a pressure-balanced pilot valve and a non-pressure-balanced main valve. Depending on the application, i.e. in particular, depending on the required injection pressure and viscosity of fuel, the modules of the servo hydraulic group can be replaced by other components with different valve concepts. This enables the alternative operation with two hydraulic pressure balanced valves for best performance at low rail pressures, or with two non-pressure-balanced valves without permanent leakage for fuels with reduced viscosity.

The nozzle assembly consists of the nozzle module taken from a serial production injector, the adapter plate and the nozzle holder carrying the nozzle spring. In addition, the nozzle holder has an integrated inductive needle lift sensor and a strain gauge based injection pressure sensor. These sensors with are used to observe and evaluate the injection process, and for the basis for an injection rate shape control using appropriate algorithms [5].

\subsection{Servo hydraulic system}

Fig. 2 shows the injector's hydraulic scheme. The piezo actuator moves a pressure balanced, spring loaded 3/2-way pilot valve with a maximum travel in the range of few $\mu \mathrm{m}$.

The position of this valve governs the pressure inside a control volume which can be adjusted to any value between drain and rail pressure. An anti-cavitation valve in the drain path increases the back pressure to a level which prevents cavitation during high pressure drops at the pilot valve's control edges. The control pressure acts on the main valve piston and opens the main valve until the resultant forces of rail pressure, control pressure and injection pressure acting on the main valve assembly are at equilibrium. Thus, the injection pressure is directly dependent on the control pressure and can be freely varied by adjusting the actuator voltage. The main valve itself is a $2 / 2$-way valve without pressure balancing to minimize leakage. When the injection pressure exceeds the nozzle needle's opening pressure preadjusted by spring tension, the nozzle opens very quickly and injection begins. For end of injection, the piezo actuator is discharged and the pilot valve is pushed back into its rest position. Since the pressure in the relatively small control volume drops very quickly, the spill valve, which was held closed against injection pressure by pilot pressure and a preloaded spring, now opens and allows for a quick pressure relief in the nozzle volume to prevent a delayed end of injection with unfavourably slowly decreasing injection pressures. Once nozzle pressure drops below the nozzle opening pressure, the needle shuts off the injector.

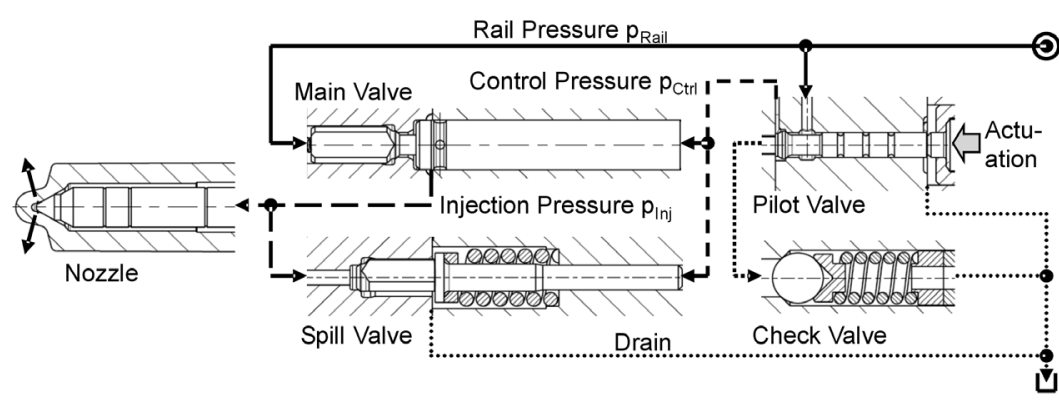

Fig. 2. Hydraulic layout 


\subsection{Material choice and manufacturing process}

Due to the utilization of high injection pressures, ensuring the mechanical durability of the injector has special importance. The crucial factor is the interaction of a high strength of the base material, a favourable macro and micro geometry of surfaces in contact with pressurized fuel and the influence of the manufacturing process.

A powder metallurgy hot work steel has been chosen for the high pressure carrying main injector components. Such high-strength steels pose extraordinary challenges to the production process, especially since many of the high pressure enclosing geometries can reasonably only be manufactured after hardening accompanied with further strength increase. For the internal high pressure ducts which are largely shaped as deep holes, sinker EDM has proved to be the only practicable method of manufacture. Being a thermal manufacturing process, however, EDM leads to some adverse effects regarding fatigue strength, such as

- thermal residual stresses leading to micro cracks

- rough surfaces in the magnitude of $\mathrm{R}_{\mathrm{z}} \approx 10 \mu \mathrm{m}$

- uncontrolled changes of the material texture up to a depth of $30 \ldots 40 \mu \mathrm{m}$.

These effects reduce the fatigue strength of the respective work piece to such an extent that loading those with the required pressures may become impossible. Therefore, as a further manufacturing step, all high pressure enclosing surfaces have been reworked using electrochemical machining (ECM), see Fig. 3. In just one step, this procedure allows to:

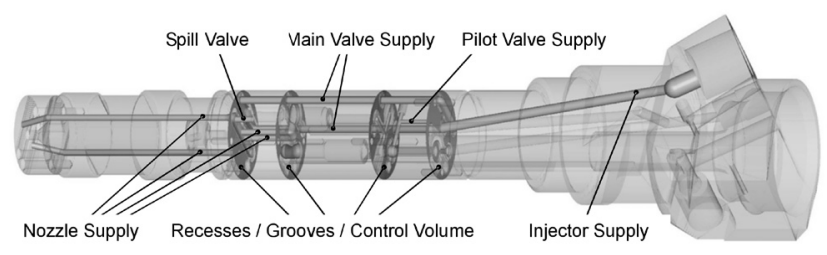

Fig. 3. ECM reworked surfaces tion quantity indicator (EMI) and an indicator tube (injection rate indicator, EVI).

\subsection{Injection quantity measurements}

Fig. 4 shows the profiles of the injection quantities over the control period of the injector when using an 8-hole nozzle with a hydraulic flow of $740 \mathrm{~cm}^{3} / \mathrm{min}$ at $100 \mathrm{bar}$. The piezoelectric actuator is driven by a rectangular voltage profile where the voltage level has been sufficiently high to yield the maximum possible injection pressure at any given rail pressure. The characteristic curves show a small

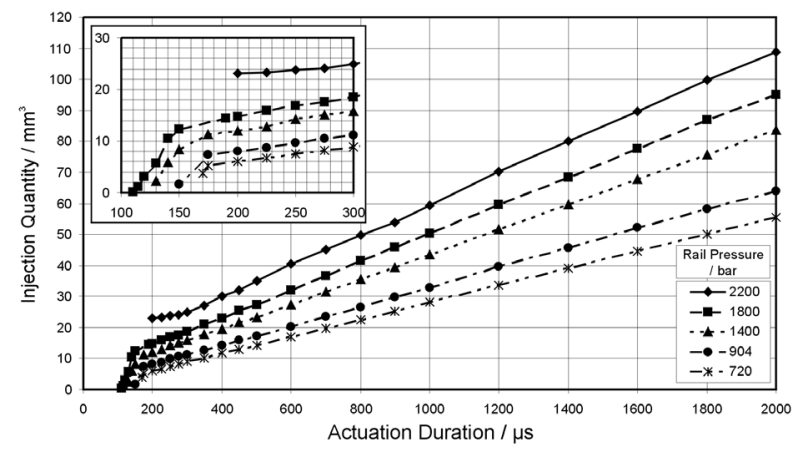

Fig. 4. Injection quantities for square actuation profile and maximum actuation voltage with 8 hole nozzle, hydraulic flow rate $740 \mathrm{~cm}^{3} / \mathrm{min}$, $0.2 \mathrm{~mm}$ max. needle lift

quantity range with relatively steep increase in the injection quantity, in which the opening and closing of the nozzle is performed by purely ballistic needle movement. This range is followed by a region with smaller quantity gradients in which the nozzle needle opens completely and remains in its open position until the end of the injection.

By actuation of the injector with lower piezo voltages, at any time, an arbitrarily chosen lower injection pressure can be utilized. This can be used, for example, to increase the metering accuracy for small injection quantities.
- ablate the surface areas damaged by the EDM process without affecting the underlying base material

- create a surface with roughness $<2 \mu \mathrm{m}$

- deburr and round the bore intersections in the inlet of the pilot valve, which has a favourable effect on both flow and fatigue strength.

\section{Hydraulic operational behaviour}

The hydraulic investigations of the HiFORS injector have been carried out in the injection laboratory of FEV GmbH using an injec-
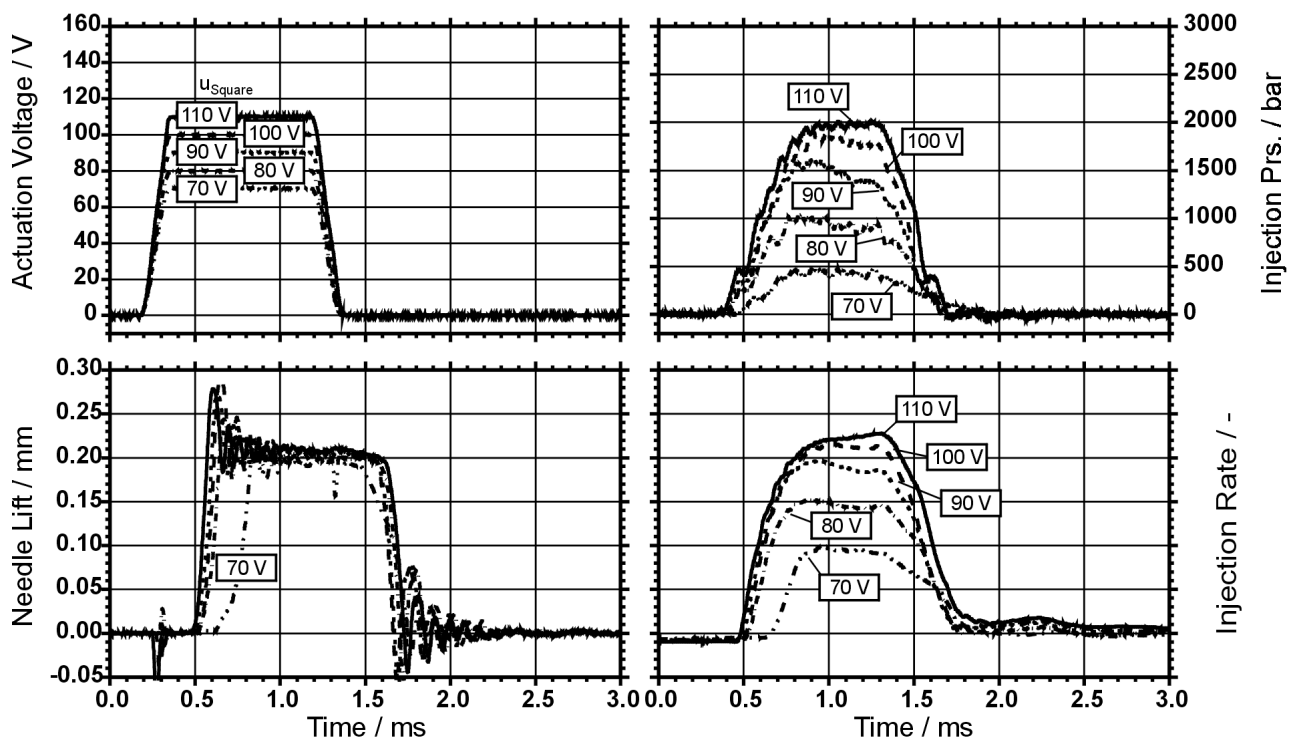

Fig. 5. Pressure modulation for square actuation profile and 2200 bar rail pressure 


\subsection{Pressure modulation}

Fig. 5 shows the effect of varying the actuation voltage for a square injection of $1 \mathrm{~ms}$ duration at a rail pressure of 2200 bar. The injection pressure measured in the nozzle body follows the voltage variation. Apart from the case of the smallest actuation voltage, in all cases the nozzle fully opens within $100 \mu$ s and closes just as quickly. EVI measurements show that the injection rate reaches its steady state value approximately $400 \mu$ s after the hydraulic start of injection and the drop of the injection rate at the end of injection has a similar duration.

Apart from the case of the smallest actuation voltage, the needle opening and closing times are virtually independent of the voltage level and take about $100 \ldots$ $150 \mu \mathrm{s}$. The bouncing effects in the needle lift signal are caused by the measurement technology and are not to be considered as individual injection events.

Fig. 6 shows the collective injection pressure map for different rail pressures and driving voltages. Each rail pressure is connected to a specific actuation voltage range in which pressure modulation is possible.

\subsection{Continuous rate shaping}

Figures 7 and 8 show variations of the typical boot and ramp injection patterns at 2200 bar. During the boot injection, the driving voltage is first raised to an intermediate level of 70, 75, or $80 \mathrm{~V}$. After a holding time of $400 \mu \mathrm{s}$, the actuation voltage is raised to $120 \mathrm{~V}$, which is the required voltage for the maximum injection pressure. The stepped increase in actuation voltage is transferred to both the injection pressure and the injection rate profiles. It is worth noting that for all actuation profiles, the falling edge of the injection pressure has almost exactly the same profile. This gives an indication of the robustness of the servo system thus demonstrates the good stability of the injection hydraulics.

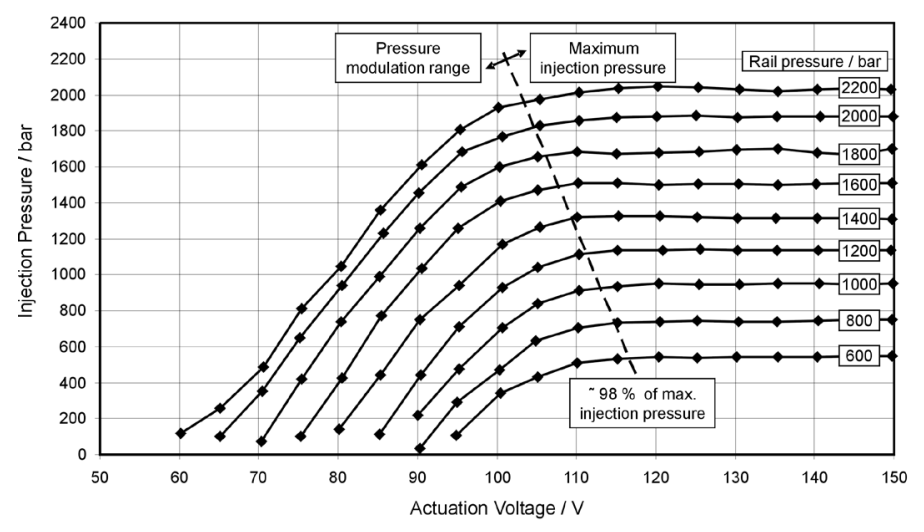

Fig. 6. Maximum injection pressure for square actuation profile in dependency of rail pressure and actuation voltage

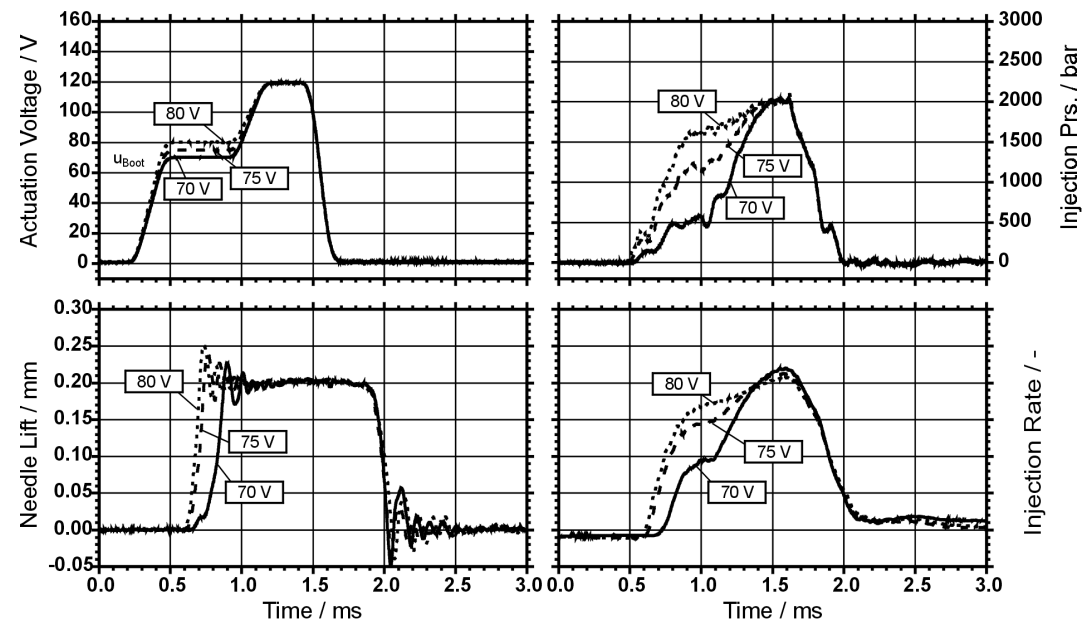

Fig. 7. Variation of boot injection profile at 2200 bar rail pressure
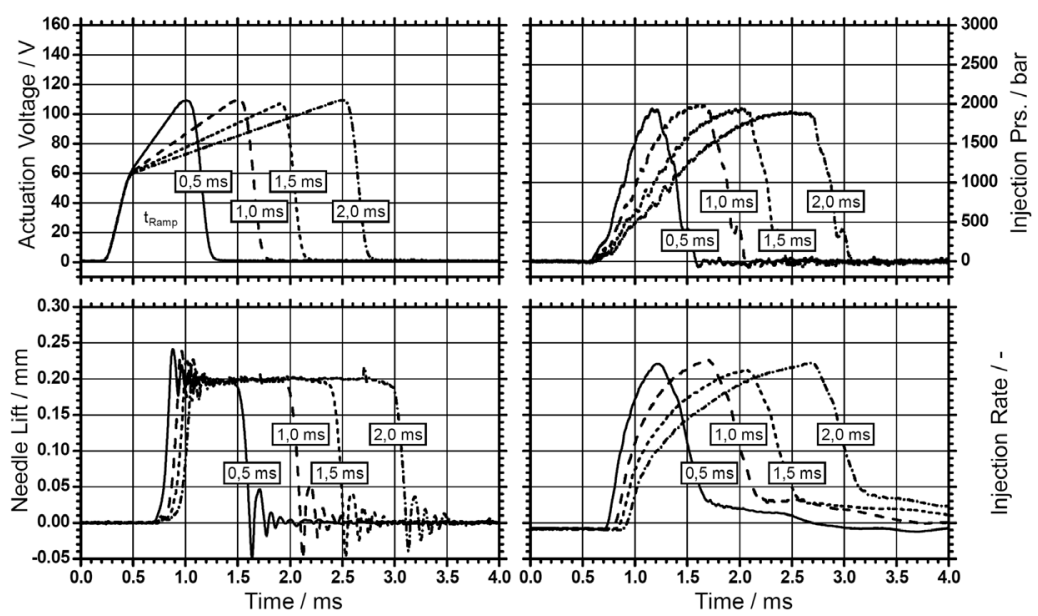

Fig. 8: Variation of ramp injection profile at 2200 bar rail pressure

For ramp shaped injection, the actuation voltage voltage is set to an intermediate threshold level before being continuously increased to the maximum level. This actuation yields continuously increasing injection pressure and injection rate curves with freely selectable gradient. By fine tuning of the actuation profile, potentially in combination with appropriate control strategies, accurately tailored injection events can be produced. These result in optimized combustion and cylinder pressure gradients which can be adapted for example to lowest pollutant and noise emissions and optimum utilization of the mechanical load capacity of the engine.

\section{Optical rate shaping investigations}

The optical investigation of the HiFORS spray and mixture formation and combustion properties were conducted in a high pressure, high temperature optically accessible combustion chamber at VKA, see Fig. 9, using a 3-hole nozzle with a total hydraulic flow of $234 \mathrm{~cm}^{3} / \mathrm{min}$ and identical spray hole geometries to the nozzle used in the single cylinder investigations. The chamber's capabilities and the data processing approaches utilized are described in detail by Graziano et al [8]. The rate shaping experiments were conducted in an air environment at 
a chamber pressure of 50 bar and temperature of $800 \mathrm{~K}$, simulating Diesel engine conditions at begin of injection during part load operation. Apart from square injection profiles, ramp and boot injection pressure shapes at rail pressure levels of 1200 and 1800 bar were used. The ramp profiles were shaped for a fixed ramp duration of $1 \mathrm{~ms}$ independent of the injection duration. The boot profiles were defined to hold approximately half rail pressure level for about half of the injection duration before quickly rising to maximum injection pressure.

The upper two diagrams in Fig. 10 show spray formation behaviour under the influence of different injection rate shapes. The individual injection durations have been chosen to yield the same injection quantities as a reference piezoelectrically actuated servo injector at a duration of actuation (DOA) of $800 \mu$ s. The liquid penetration length of the injection sprays shows no obvious dependency on neither rail pressure level nor rate shaping profile; this aligns with literature, e.g. [9] where it was found that the liquid spray length is solely dependent on spray hole diameter, physical fuel properties and the thermodynamic state of the cylinder charge. The gaseous spray penetration however results from
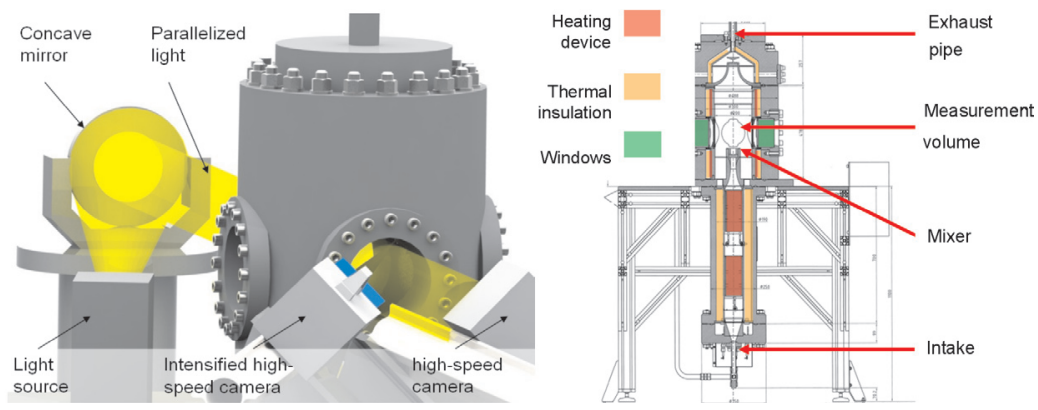

Fig. 9. Optical chamber set-up
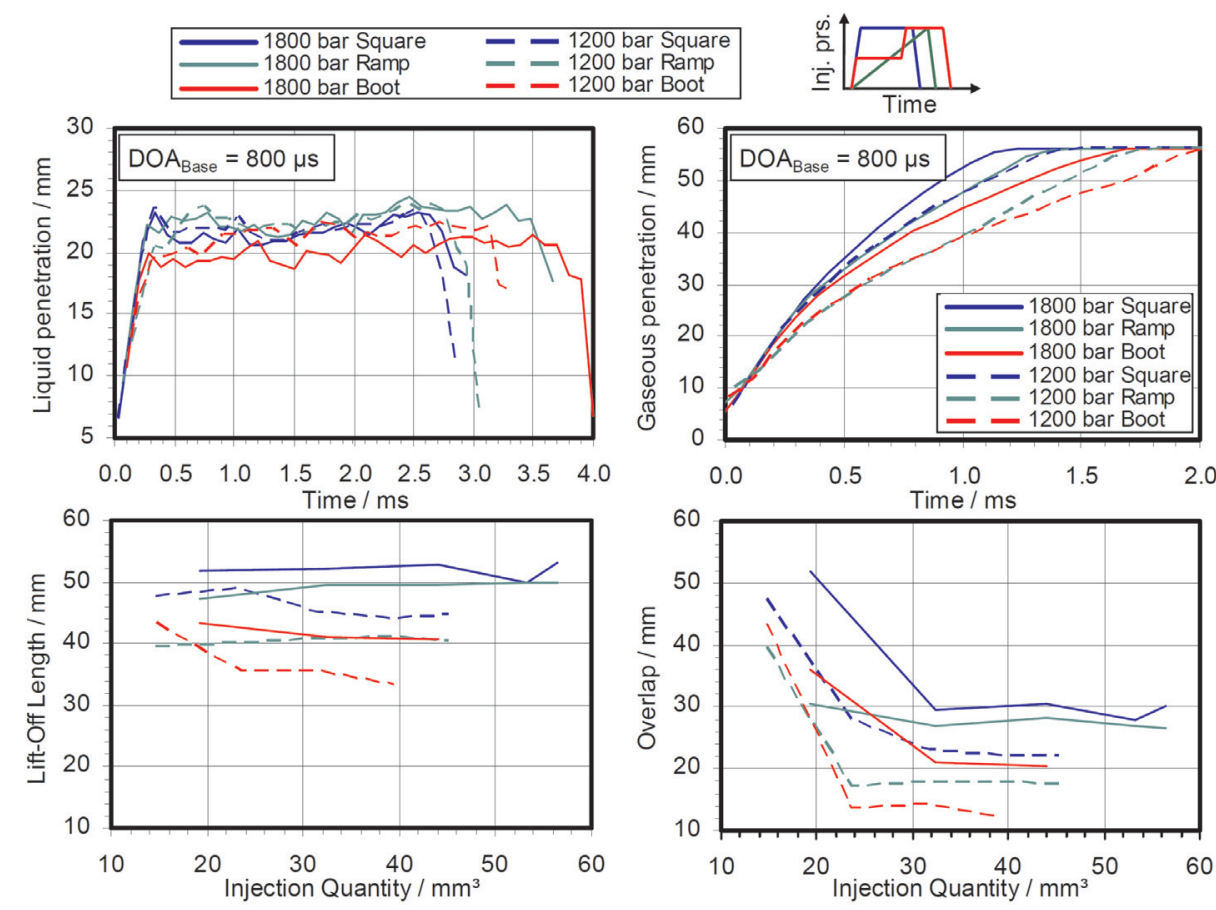

Fig. 10. Optical investigation results for different injection rate shapes and injection pressures the impulse exchange between liquid and surrounding gas including the entrainment of ambient air and therefore shows a strong dependence on rail pressure and injection pressure profiles. As a consequence of combustion starting in the gaseous portion of the spray, both lift-off length (i.e. distance from nozzle tip to combustion zone) and overlap (distance from the tip of the liquid spray core to the combustion zone) are reduced for lower rail pressures as well as for rate shaping injection with reduced effective injection pressure at the beginning of injection. Since these values are indicators for the available distance and time for mixture preparation, they explain the tendency of increased soot formation due to non-sufficient oxygen availability when employing rate shaping in engine operation.

\section{Single cylinder engine investigations}

\subsection{Experimental design}

The single cylinder engine investigations were carried out on a 4-valve, $390 \mathrm{~cm}^{3}$ engine with a compression ratio of 15 . The part load point definition by engine speed and internal mean effective pressure (IMEP) covers the main operation range for relevant test cycles in a hypothetical C-class vehicle as introduced by [4]; this includes fixed centers of combustion taken from the engine's reference calibration with a close-to-production piezoelectrically driven servo injector as well as target values for $\mathrm{NO}_{\mathrm{x}}$ emissions for meeting EURO6 emission legislation, see Tab. 1.

The part load operating points are used for comparing the HiFORS injector's performance against the reference injector without the use of rate shaping as well as the potential analysis of rate shaping profiles in the higher load operating points PL3 and PL4. The HiFORS injector's high pressure capability is explored in three full load operating points at 2000,3000, and $4000 \mathrm{~min}^{-1}$ by increasing engine load as far as possible within given peak pressure, soot, and exhaust gas temperature limits. All investigations were carried out using a close to production nozzle module with a hydraulic flow rate of $625 \mathrm{~cm}^{3} / \mathrm{min}$ on both reference and HiFORS injectors.

\subsection{Base investigations}

The base investigations were carried out in form of exhaust gas recirculation (EGR) sweeps in the defined part 
Tab. 1. Single cylinder engine operating point definition

\begin{tabular}{|l|c|c|c|c|c|c|}
\hline \multirow{3}{*}{ Operating point } & Engine speed & IMEP & $\mathrm{p}_{\text {Rail }}$ & $\mathrm{p}_{\text {Intake }}$ & Center of Combustion & ${\text { Spec. } \mathrm{NO}_{\mathrm{x}} \text { target }}$ \\
\cline { 2 - 7 } & $\mathrm{min}^{-1}$ & bar & bar & bar & ${ }^{\circ} \mathrm{CAATDC}$ & $\mathrm{g} / \mathrm{kWh}$ \\
\hline PL1 & 1500 & 4.3 & 720 & 1.07 & 5.8 & 0.2 \\
\hline PL2 & 1500 & 6.8 & 904 & 1.50 & 6.6 & 0.2 \\
\hline PL3 & 2280 & 9.4 & 1399 & 2.29 & 9.2 & 0.4 \\
\hline PL4 & 2400 & 14.8 & 1800 & 2.60 & 10.8 & 0.6 \\
\hline FL1 & 2000 & 27.0 (ref.) & 1800 (ref.) & 2.46 & - & - \\
\hline FL2 & 3000 & 29.0 (ref.) & 2000 (ref.) & 2.70 & - & - \\
\hline FL3 & 4000 & 28.6 (ref.) & 2000 (ref.) & 3.00 & - & - \\
\hline
\end{tabular}

load operating points using a reference piezoelectrically actuated servo injector with and without pilot injection and the HiFORS injector without pilot injection. Due to the HiFORS injector's hydraulic layout, the needle opens while nozzle pressure is still being built up, resulting in a steep ramp-shaped injection pressure trace similar to former cam-driven UI systems even for rectangular actuation voltage profiles. As a consequence, the mass flow rate during
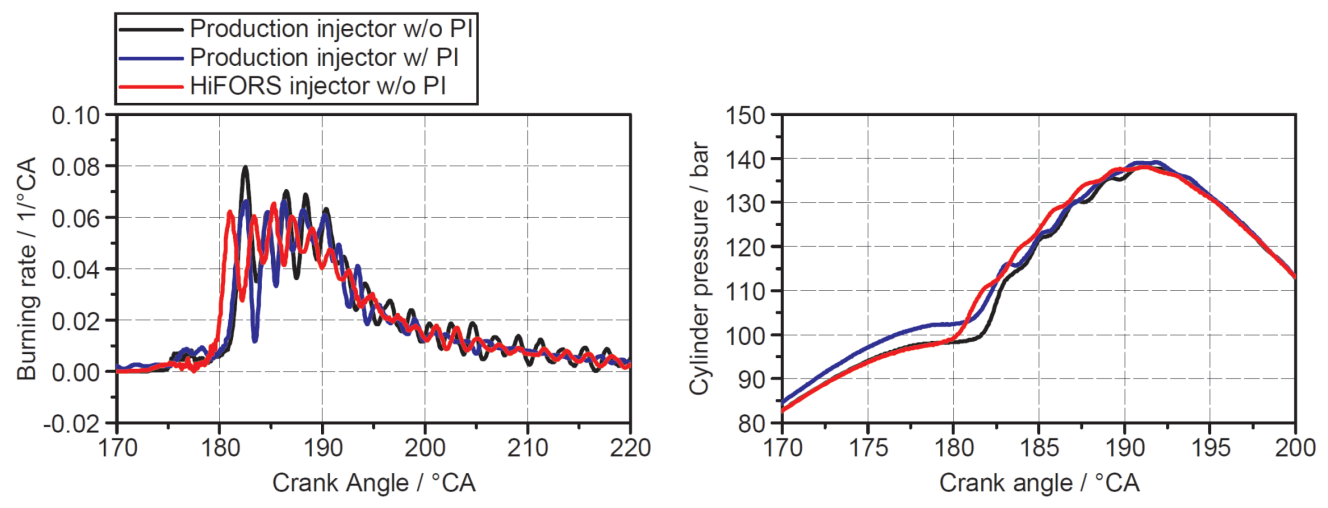

Fig. 11. Burning rate and cylinder pressure traces for HiFORS and production injectors at part load operating point PL4, indicated specific $\mathrm{NO}_{\mathrm{x}}$ emissions $\approx 0.5 \mathrm{~g} / \mathrm{kWh}$ relatively quick needle operation without long times under the effect of seat throttling, resulting in excellent mixture formation from the very beginning of injection. Only in high part load point PL4, the HiFORS injector's soot emissions are higher than both reference injections. This might be caused by higher internal pressure losses between fuel supply and nozzle which become evident at longer injection durations when nozzle opening and closing effects have less impact. The combustion sound level is in all operating points comparable to the reference injector with pilot injection, thus confirming the approach of omitting the pilot injection for the HiFORS injector. The indicated efficiency of the HiFORS injector also follows the reference injector with pilot injection in points PL2 ignition delay is reduced, with the effect of reduced maximum burning rate and a less steep cylinder pressure gradient very similar to the reference injection with pilot event, see Fig. 11. An additional pilot injection for the HiFORS injector is therefore considered obsolete.

Fig. 12 shows overall results of the EGR sweeps when recalculated to the respective specific $\mathrm{NO}_{\mathrm{x}}$ targets for EURO6 calibration. While point FL1 shows no reasonably measurable soot emissions at all for all injection patterns, in part load points FL2 to FL3 the filter smoke numbers of the HiFORS injector are even lower than those of the reference injector with single main injection; this is contributed to the
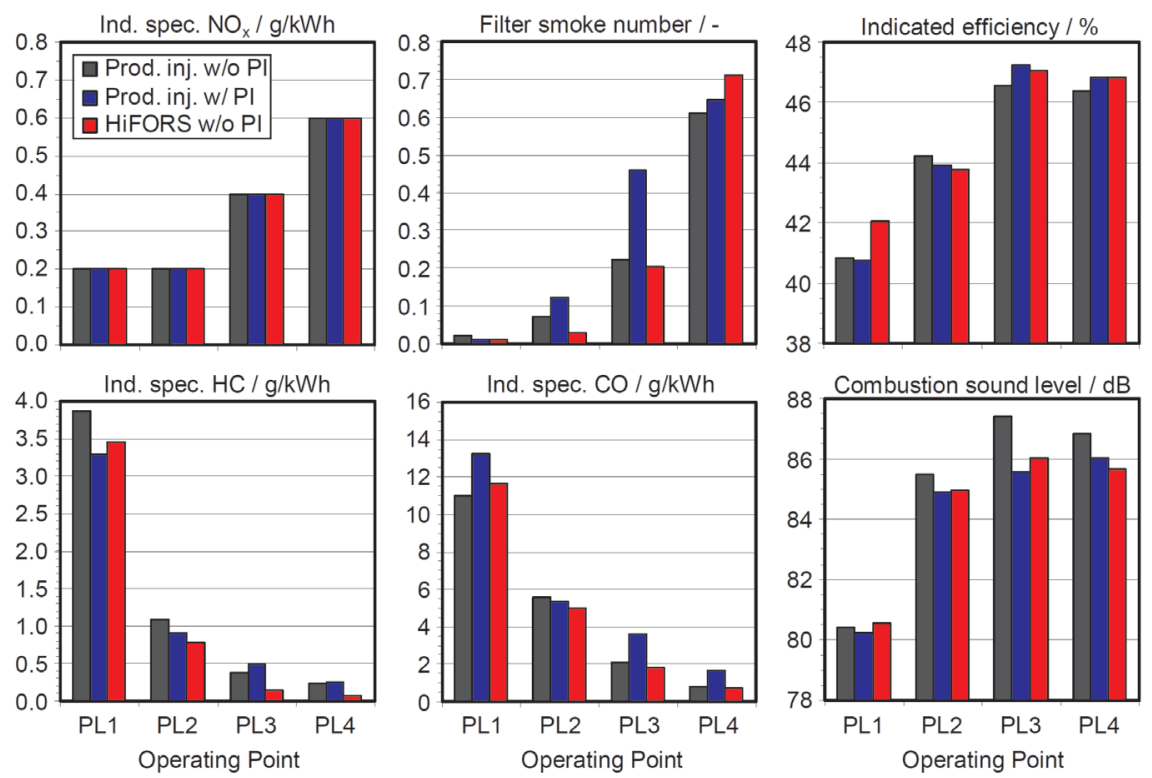

Fig. 12: Emissions, efficiency and combustion sound at part load operation for HiFORS and production injectors 


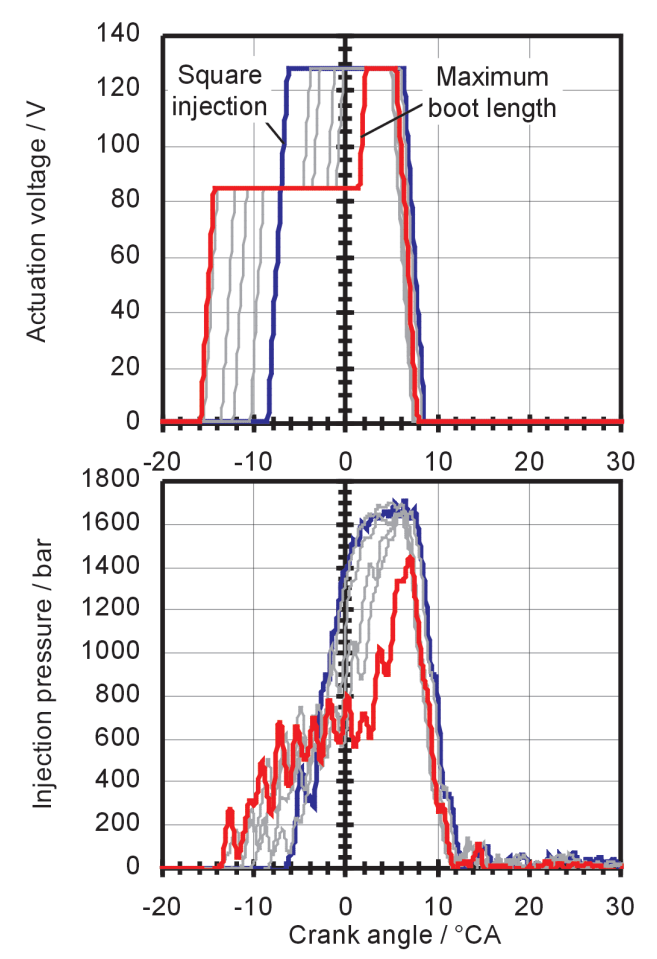

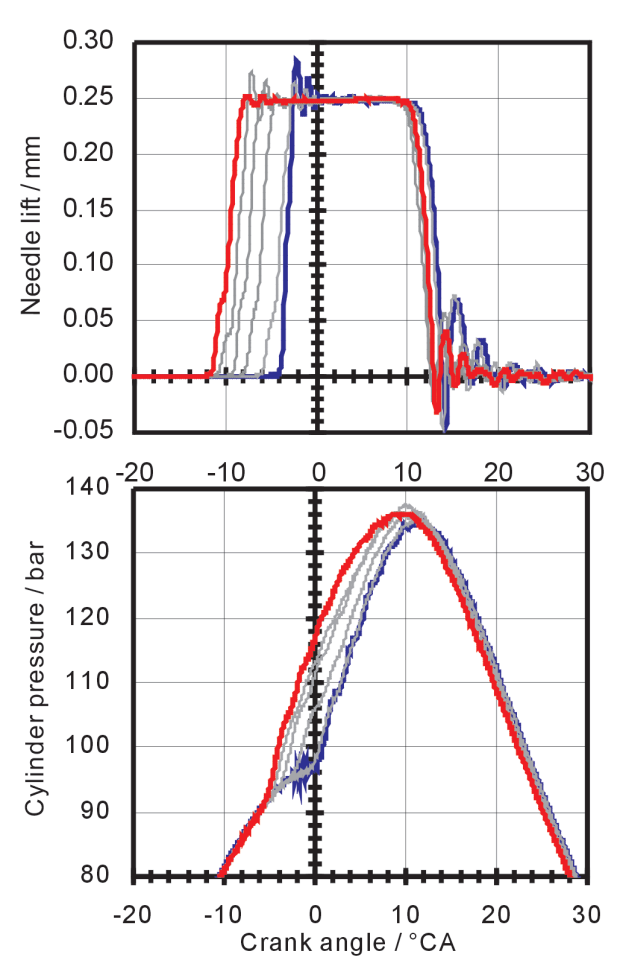

Fig. 13. Low boot rate shaping variation at part load operating point PL4. Blue: square injection profile; red: maximum boot length injection profile; grey: intermediate injection profiles role compared to purely performance driven requirements which prefer rectangular injection profiles. In both points, variations of the ramp profile with decreasing slope steepness and low, medium, and high boot profiles with increasing boot level durations were investigated. All values shown in Tab. 1 including the indicated $\mathrm{NO}_{\mathrm{x}}$ emission level were fixed throughout the variations by adaptation of begin and duration of injection and EGR rate. Fig. 13 shows the example of the low level boot profile variation at PL4. The investigation starts with a square injection (blue curve) and the typical resultant cylinder pressure profile of

to PL4, while in the low load point PL1, with short injection duration and therefore high importance of needle opening and closing behaviour, the HiFORS injector has significant advantages.

\subsection{Rate shaping}

Rate shaping investigations were carried out in higher part load operating points PL3 and PL4 where injection duration is sufficiently long to allow for significant alterations of the injection rate shape while, in contrast to full load conditions, combustion sound and $\mathrm{NO}_{\mathrm{x}}$ reduction still play a

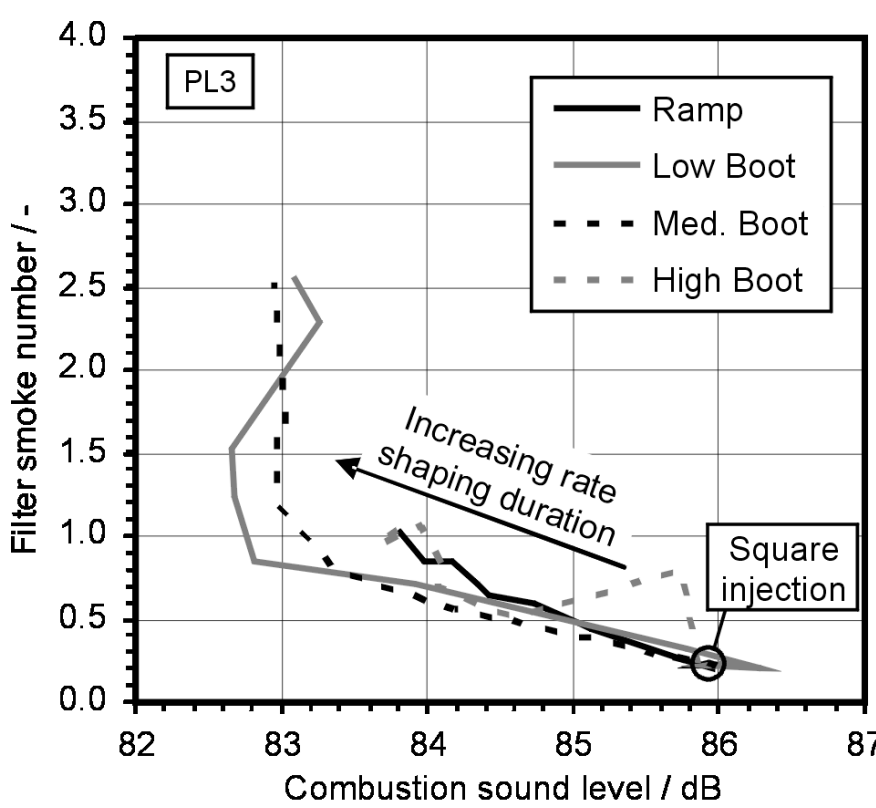

Fig. 14: Soot-sound trade-off for different injection rate shapes at part load operating points PL3 and PL4 

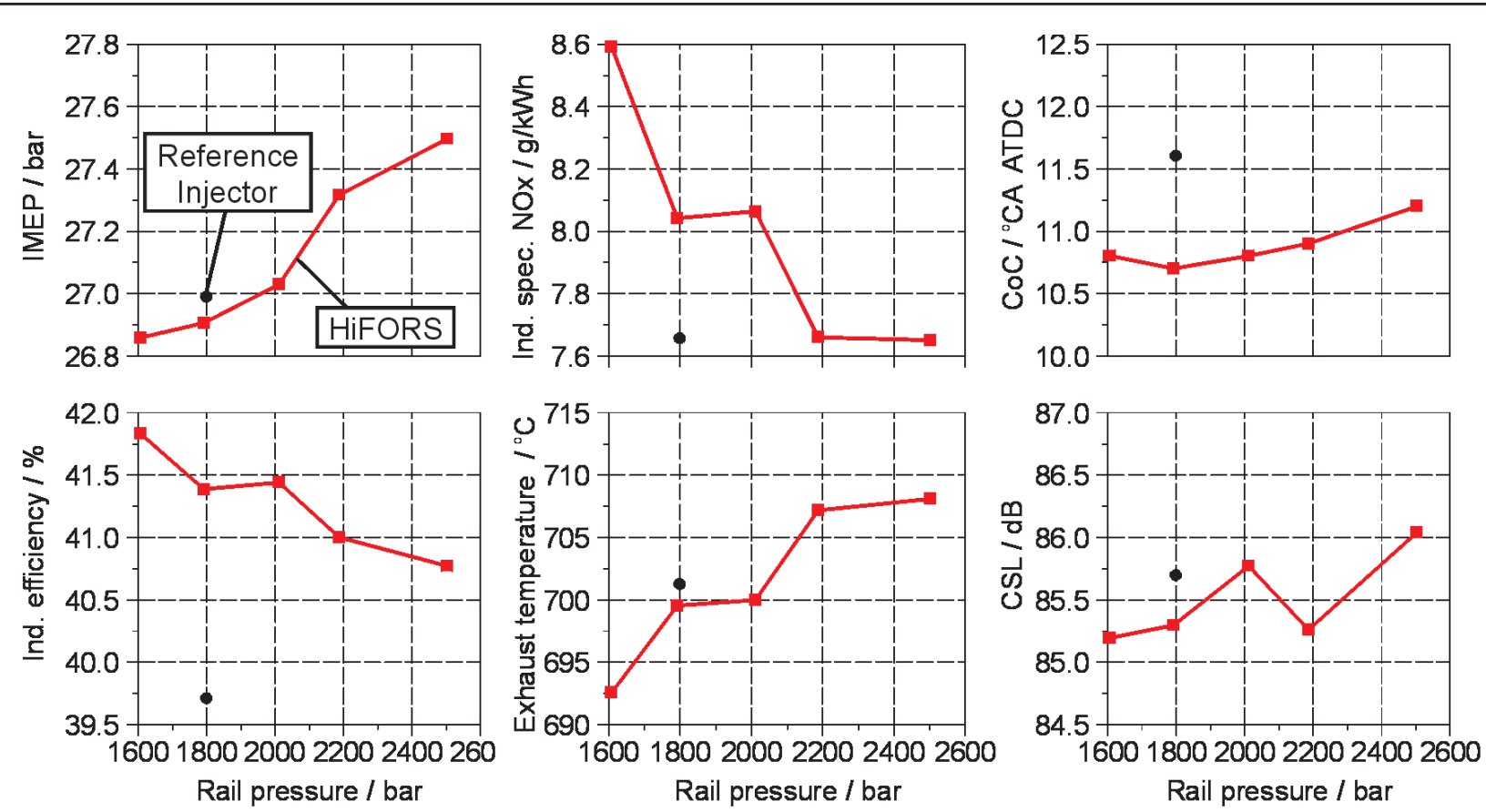

Fig. 15. Single cylinder engine behaviour at full load operating point FL1

cylinder pressure rise caused by combustion starts earlier and tends to form a less steep pressure rise gradient. The profile variation is ended when rate shaping duration becomes so long that the injection pressure does not reach the maximum defined by the square injection anymore (red curve).

Since combustion sound reduction at moderate drawbacks especially in soot emission is one of the main aims of injection rate shaping, the relation between these two parameters is shown in Fig. 14 for both rate shaping part load operating points. In both cases, the variation start with square injection profiles in the lower right-hand corner at low soot emissions and relatively high combustion sound levels. By applying rate shaping patterns with increasing shaping durations, the combustion yields reduced sound levels and increased soot emissions. All profiles follow very similar operating point dependant paths within the measurement fluctuations. However, in both cases the ramp variations only show limited capability in altering the engine's soot-sound behaviour, the same applies for the high boot profiles in PL3.

The variation trajectories for PL3 and PL4 have quite different characteristics. At PL3, sound level improvement can only be achieved by increasing soot emissions up to a point where further rate shaping only leads to more soot without any more sound benefit, with the critical parameters placed at about $83 \mathrm{~dB}$ and a filter smoke number of 1.0. At PL4, the potential for combustion sound reduction at limited additional soot emissions is smaller, but using the medium boot level there is the possibility to lower combustion sound by $1 \mathrm{~dB}$ without any drawbacks in soot formation.

\subsection{Full Load Operation}

In the full load operating points, the potential of significantly increased rail pressures on engine performance is investigated. The operating points are defined by engine speed and upper limits for cylinder peak pressure, exhaust temperature and soot emissions, while engine load is increased in combination with adaptation of center of combustion as far as possible within these limits. For the exemplary full load operating point FL1 shown in Fig. 15, the effective limits are peak cylinder pressure at 180 bar and a maximum filter smoke number of 1.0. The rail pressure for the HiFORS injector is varied from 1600 to 2500 bar, while the reference injector was operated at 1800 bar rail pressure.

The results show that by using increased injection pressures, the maximum engine load can be increased from around 26.85 bar IMEP at 1600 bar rail pressure to 27.5 bar at 2500 bar rail pressure, thus improving the indicated engine full load performance by $2.4 \%$ without any need to improve the thermal or mechanical capabilities of engine components. To stay within peak pressure limits, the center of combustion $(\mathrm{CoC})$ has to be slightly shifted from around 10.75 to $11.25^{\circ} \mathrm{CAATDC}$, resulting in an increase of exhaust temperature from 692.5 to $708^{\circ} \mathrm{C}$ and consequently a drop of indicated efficiency from 41.8 to $40.8 \%$. Due to the shift of combustion center and therefore lower peak cylinder temperature, the indicated $\mathrm{NO}_{\mathrm{x}}$ emissions are lowered from 8.6 to $7.65 \mathrm{~g} / \mathrm{kWh}$ while higher cylinder pressure gradients during combustion at increased injection pressure lead to higher combustion sound level of 86.0 at 2500 bar rail pressure compared to 85.25 at 1600 bar.

Compared to the reference injector, the HiFORS injector's high injection pressure capability enables higher engine full load performance at better indicated efficiency although the combustion center has to be shifted to later points at highest rail pressures. Given a fixed full load target, this opens up the possibility to optimize the combustion process by using nozzles with smaller hydraulic flow rates which improve operation behavior within the whole engine operation range. 
As another conclusion, for optimized utilization of highest injection pressures at full load conditions, the respective engine's peak pressure capability should be increased to avoid the need for combustion center shift with its impact on engine efficiency.

\section{Summary and Outlook}

FEV GmbH and the Institute for Combustion Engines, RWTH Aachen University, have developed the HiFORS injector as a highly flexible research tool for developing and testing modern diesel combustion processes. The piezoelectrically actuated injector contains a spring-loaded nozzle needle with an upstream control valve which not only governs the start and duration of injection of injection, but also the flexible injection rate. The rapid opening and closing action of the nozzle needle, ensures short times in the area of small needle lifts even at small injection rates, so that the harmful influence of needle seat throttling can be largely minimized.

The presented injector is capable of injection pressures of up to 2500 bar. This pressure capability has been achieved by appropriate manufacturing processes and special surface treatment of all high pressure containing volumes. Furthermore, the leakage losses have been significantly minimized, thus making it possible to significantly reduce the thermal load of the injector.

The capability of the injector regarding high injection pressures and flexible rate shaping and is proven by injection test rig investigations. The influence of injection at different rail pressure levels with variable injection rate profiles on mixture formation and combustion in a laboratory environment is investigated by high pressure, high temperature optical chamber experiments. While the liquid spray core length remains constant for all variations, both reduced rail pressures and rate shaping approaches decrease gaseous spray penetration, resulting in combustion start closer to the nozzle tip with less spray development time and length needed for optimum mixture formation.

The new injector's impact on engine operation is analyzed using a single cylinder research engine. Injector performance is tested against a piezoelectrically actuated close to production servo injector using identical nozzles. Base EGR sweeps show significant advantages in $\mathrm{NO}_{\mathrm{x}}$-soot trade-off in low to medium part loads while maintaining combustion sound level and indicated efficiency of a standard injection pattern with pilot injection. The continuous rate shaping functionality opens additional potential for combustion sound reduction at moderately increased soot emissions. At full load operation, the injector's high pressure capability enables both increased engine performance and improved indicated efficiency compared to the reference injector.

Next steps will include the integration of the HiFORS injector into advanced closed-loop combustion control systems $[5,10]$, thereby fully exploring the ability of continuous rate shaping to form an optimum Diesel combustion process.

\section{Acknowledgment}

The research leading to these results has received funding from the European Union Seventh Framework Programme [FP7/2007-2011] under grant agreement No. 234032.

\section{References}

[1] Matsumoto S. et al.: Der neue Diesel-Magnetventil-Injektor von Denso. In: MTZ - Motortechnische Zeitschrift 74 (2) (pp. 146-150), 2013.

[2] Predelli O. et al.: Kontinuierliche Einspritzverlaufsformung in Pkw-Dieselmotoren - Potenziale, Grenzen und Realisierungschancen. In: 31. Internationales Wiener Motorensymposium, Vienna 2010.

[3] Herrmann O.E. et al.: Ultra High Pressure Fuel Injection for minimized Engine-Out Emissions of HD Diesel Engines. In: Diesel and Gasoline Direct Injection VI, Berlin 2010.

[4] Rottmann M.: Einspritzratenformung am schnelllaufenden DI-Dieselmotor. PhD thesis, RWTH Aachen 2011.

[5] Hinkelbein J.: Entwicklung einer Verbrennungscharakteristikregelung mittels Einspritzver-laufsmodulation bei direkteinspritzenden Dieselmotoren. PhD thesis, RWTH Aachen 2010.

Paul Grzeschik, Dipl.-Ing. - Project Engineer Engine Design. Institute for Combustion Engines, RWTH Aachen University.

e-mail: grzeschik@vka.rwth-aachen.de
[6] Kremer F. et al.: Verbrennungsratenregelung - Baustein zur weiteren Komfortsteigerung $\mathrm{CO}_{2}$-optimierter Dieselmotoren. In: Engine Combustion Processes X, Munich 2011.

[7] Laumen H.-J. et al.: Flexible Einspritzverlaufsformung - Auch bei PKW-Dieselmotoren ein wirkungsvolles Mittel zur Reduzierung von Verbrauch und Schadstoffemissionen? In: Diesel and Gasoline Direct Injection IV, Berlin 2006.

[8] Graziano B. et al.: Investigation on the Ignition Sensitivity of 2-MTHF, Heptane and Di-n-butylether. In: Proceedings of the European Combustion Meeting 2013, Lund 2013.

[9] Siebers D.L.: Scaling Liquid-Phase Fuel Penetration in Diesel Sprays based on Mixing-Limited Vaporization. SAE Technical Paper Series 1999-01-0528, 1999.

[10] Schnorbus T.G.: Zylinderdruckgeführtes Einspritzmanagement beim Dieselmotor. PhD thesis, RWTH Aachen University 2010 .

Hermann-Josef Laumen, Dr.-Ing. - Senior Technical Specialist Fuel Injection Systems. FEV GmbH.

e-mail:laumen@fev.com

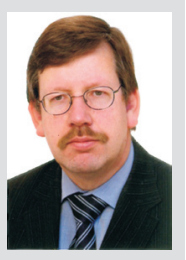

